\title{
PREVALENCE OF TAURODONTISM IN AN EGYPTIAN POPULATION PERMANENT MOLAR TEETH
}

\author{
Khaled Ali Beshr ${ }^{*}$ and Hossam Mossa **
}

\begin{abstract}
Objectives: Taurodontism is a dental anomaly used to describe vertically elongated pulp chamber with apically positioned pulpal floor and absence of the usual constriction at the cementoenamel junction (CEJ). It commonly involved permanent molar teeth especially mandibular molars.
\end{abstract}

Aim: This study was aimed to investigate the Prevalence of Taurodontism in an Egyptian Population permanent molar teeth.

Study Design: 1560 patients, from age between 18 to 40 years old were examined by panoramic radiographs for the existence of taurodontism

Results: Taurodontism was found in 9 patients with a Prevalence of $0.6 \%$ and $0.38 \%$ of which were males and $0.12 \%$ females. Taurodontism was significantly more common in mandible than in maxilla.

Conclusion: Taurodontism in the Egyptian population is relatively uncommon phenomena.

KEY WORDS: Taurodontism, prevalence, permanent mandibular molars, permanent maxillary molars

\section{INTRODUCTION}

The term taurodontism firstly applied to describe the tooth with large, elongated pulp chamber in-combination with short roots and root canals ${ }^{(1)}$. Taurodontism is a morphological anomaly and/or developmental disturbance of a tooth that characterized by; absence of the usual cementoenamel junction (CEJ) constriction ${ }^{(1,2)}$. In spite of normal crown size, the pulp chamber floor and furcation area are positioned more apically than normal, and roots of the teeth and their canals become shorter in length ${ }^{(1,2)}$.

Numerous theories tray to explain the etiology of taurodontism. Some authors claimed that; it is due to genetic factors or mutations ${ }^{(3-5)}$. Other authors postulated that; epithelial root sheath of Hertwig's diaphragm failure to in-folding the proper horizontal level during root formation ${ }^{(6)}$, but the definite

* Lecturer of Endodontics, Faculty of Dentistry, Beni Suef University

** Department of Restorative Dental Science, Alfarabi Colleges, Riyadh - Kingdom of Saudi Arabia. 
cause is still unclear. However; taurodontism has been reported with several genetic disorders and syndromes, for example; Amylogenesis imperfecta, Ectodermal dysplasia and Down's syndrome ${ }^{(7,8)}$.

Taurodontism can affect all teeth; often involve the permanent dentition more than deciduous one (9-11). It is commonly affect mandibular permanent molars ${ }^{(2)}$, and it may be unilateral or bilateral ${ }^{(12)}$.

Taurodontism can be classified according to the degree of apical displacement of the pulpal floor into mild, moderate and severe ${ }^{(13,14)}$. Neville et al. also claimed that; The degree of taurodontism increases from the first to the third molar ${ }^{(15)}$.

Clinically,taurodontic-teeth cannotberecognized and appears as normal teeth, with normal crown size (12). So, diagnosis of taurodontism is usually done by the help of radiographs ${ }^{(15)}$, especially with advanced radiographic devices as cone beam computed tomography, which more effective for diagnosis and treatment of taurodontic-teeth, because their roots can be separately visualized ${ }^{(16)}$.

Endodontics treatment and its related surgical procedures changed in case of taurodontic-tooth rather than normal one, due to the changed structure, shape and size of the taurodontic-tooth ${ }^{(17-19)}$.

The present study aimed to assess the commonness of taurodontism of permanent molars in an Egyptian population using panoramic radiograph examination.

\section{METHODS:}

The data collection will be obtained from the data base available at Oral \& Maxillofacial Radiology department at faculty of Dentistry Beni suef university and Al-Azhar university .

The data of 1560 patients between January 2013 to October 2018 were examined using panoramic radiographs, then collected and recorded for this study. The patients age ranged from 18 to 40 years. Any teeth with confused or undetectable furcation area (teeth with fused roots, impacted teeth, teeth with root resorption and fractured teeth) were excluded from this study. Also, any panoramic radiograph with improper defect as; elongation, distortion, overexposed or underexposed were not included in our study.

All radiographs were subsequently reviewed and evaluated using the criteria of Shifman and Chanannel for taurodontism ${ }^{(20)}$.

The collected data were analyzed using SPSS (SPSS Inc. Chicago, USA).

\section{RESULTS}

This study included of 935 males (59.9\%) and 625 females $(40.1 \%)$ with an age range of 16 to 40 years. Taurodontism was found in panoramic radiograph (Figure 1) in a total of 9 patients with a frequentness of $0.6 \%$ of which $6(0.38 \%)$ were males and $3(0.12 \%)$ females. Taurodontism was unilateral in about five cases ( 3 females and 2 males) with a prevalence of $(55.5 \%)$, while the bilateral taurodontism was fond in four male cases a prevalence of $(44.5 \%)$.

There was statistically significant difference ( $p>0.05)$ in the distribution between the male and female gender. Only, thirteen molar teeth of the 1560 case that were radiographically investigated showed taurodontism. Taurodonts were significantly $(\mathrm{p}<0.05)$ more common in the mandible $(77 \%)$ than in the maxilla (23\%) (Table 1). The mandibular first and second molar (61.6\%) were the most commonly involved teeth. Only 3 maxillary molars (23\%) and 2 mandibular third molars (15.4\%) were involved. 
TABLE (1) Taurodonts distribution in mandible and maxilla according to the affected molar-tooth.

\begin{tabular}{|l|c|c|c|c|c|c|}
\hline & \multicolumn{2}{|c|}{ Mandible } & \multicolumn{2}{c|}{ Maxilla } & \multicolumn{2}{c|}{ Total } \\
\hline Tooth & No. & $\%$ & No. & $\%$ & 5 & 38.5 \\
\hline First molar & 4 & 30.8 & 1 & 7.6 & 6 & 46.1 \\
\hline Second molar & 4 & 30.8 & 2 & 15.4 & 2 & 15.4 \\
\hline Third molar & 2 & 15.4 & 0 & 0 & 13 & 100 \\
\hline Total & 10 & 77 & 3 & 23 & 3 \\
\hline
\end{tabular}

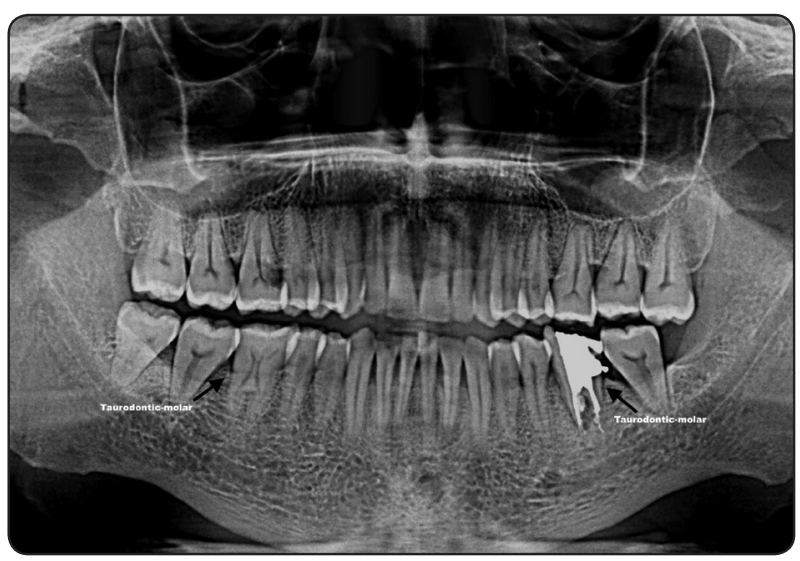

Fig. (1) Panoramic view shows bilateral taurodontism in first mandibular molars.

\section{DISCUSSION}

Taurodontism more common in permanent teeth more than deciduous one ${ }^{(21,22,23)}$, and additionally it more common posterior teeth (pre-molars and molars) ${ }^{(22)}$. According to our study; taurodontism more common in male more than female in Egyptian population (Table 1), while other studies in others population (German and Asian), taurodontism was more common in female ${ }^{(22,24,25)}$.

Anterior region is difficult to be diagnosis by using panoramic radiographs because, it may become distorted during the radiographic examination and may introduce false diagnosis of taurodontic tooth ${ }^{(26,27)}$. In this study, only permanent molars were examined (Figure 1).
Taurodontic molar teeth exhibit a great challenge during endodontic treatment and need special handling procedures because the close proximity their orifices and apical displacement of the roots ${ }^{(1,27,28)}$. From an endodontist's view; the taurodontic molar teeth showing a more complicated root canal treatment than normal one, because their canals were very short with close orifices ${ }^{(8,27,28)}$. The instrumentation of the taurodont tooth was difficult and time consuming, because, only the apical third of the file used during instrumentation ${ }^{(29)}$.

Surgical microscopes and magnifying loupes which used as magnification devices can play a very important role to locate orifices of root canals and evaluate the floor of pulp chamber ${ }^{(22,30)}$. The obturation may be improved by using the thermoplastic gutta-percha in these cases ${ }^{(22,30,31)}$.

\section{CONCLUSION}

Taurodontism commonness in in the present study was $0.6 \%$. Also, it was familiar in male than female and in mandible than maxilla in Egyptian population. Whatever, the frequentness of taurodontism, it is very important for an endodontist to be aware about taurodontism and its clinical complications. 
Future Suggestions: Further large scale studies in the general Egyptian population need to be carried out to assess its commonness. Also; family history of other developmental anomalies and genetic disorders should also be considered for involved patients.

\section{REFERENCES}

1- Patil S, Doni B, Kaswan S, Rahman F. Prevalence of taurodontism in the North Indian population. J Clin Exp Dent. 2013;5(4): e179-82.

2- Rao A, Arathi R. Taurodontism of deciduous and permanent molars: report of two cases. J Indi Soci Pedodo Prevent Dent. 2006);24: 42-4.

3- Akintoye S O, Lee J S, Feimster T, Booher S, Brahim J, Kingman A, et al. Dental characteristics of fibrous dysplasia Mc Cune-Albright. Syndrome. Oral Surg Oral Med Oral Pathol Oral Radiol. 2003; 96: 275-82.

4- Axelsson S, Bjornland T, Kjaer I, Heiberg A, Storhaug K. Dental characteristics in Williams syndrome: a clinical and radiographic evaluation. Acta Odontol Scand. 2003; 61:129-36.

5- Constant D A, Grine F E. A review of taurodontism with new data on indigenous southern Arican populations. Archives of Oral Biology. 2001;46(11): 1021-9.

6- Kan W Y, Seow W K, Holcombe T. Taurodontism in children with hypodontia and supernumerary teeth: a case control study. Pediatr Dent. 2010; 32:134-40.

7- Andersson E, Axelsson S, Gjolstad L, Storhaug K. Taurodontism: A minor diagnostic criterion in Laurencemoon/Bardet Biedl syndromes. Acta Odontol Scand. 2013;71(6): 1671-4

8- Joseph M. Endodontic treatment in three taurodontic teeth associated with 48, XXXY Klinefilter syndrome: a review and case report. Oral Surg Oral Med Oral Pathol Oral Radiol Endod. 2008; 105: 670-7.

9- Dervazeh A M. Prevalence of taurodontism in Jordanian Dental patients. Dento Maxillofac Radiol. 1998; 27:163-5.

10- Goz P W, White S C. Oral Radiology (Principle and interpretation), 3rd ed. St. Louis, Missouri: C.V. Mosby Year Book Inc; 1994.

11- Mac Donald-Jankowski DS, Li TT. Taurodontism in a young adult Chinese population. Dento Maxillo Radiol $1993 ; 22: 140-4$.
12- White SC, Pharoah MJ (2004) Oral Radiology. Principles and Interpretation, 5th ed. St. Louis, USA: Mosby.

13- Ronald WK, Yada C, Linda R. Localized deficient root development associated with taurodontism - A case report. Pediatr Dent 1999; 21:213-5.

14- Goz P W, White S C. Oral Radiology (Principle and interpretation), 3rd ed. St. Louis, Missouri: C.V. Mosby Year Book Inc; 1994.

15- Neville B W, Damm D D, Allen C M, Bouquot J E (2002) Oral and Maxillofacial Pathology, 5th ed. Philadelphia: W.B. Saunders.

16- Patel S, Dawood A, Ford T P, Whaites E (2007) The potential applications of cone beam computed tomography in the management of endodontic problems. Int Endod J $40,818-830$.

17- Guttal K S, Naikmasur V G, Bhargava P, Bathi R J. Frequency of developmental dental anomalies in the Indian population. Eur J Dent. 2010; 4: 263-9.

18- Kathariya M D, Niknam A P, Chopra K, Patil N N, Raheja $\mathrm{H}$, Kathariya R. Prevalence of dental anomalies among school going children in India. J Int Oral Health. 2013; 5: $10-14$.

19- Goncalves-Filho A J, Moda L B, Oliveira R P, Ribeiro A L, Pinheiro J J, Alver-Junior S R. Prevalence of dental anomalies on panoramic radiographs in a population of the state of Pará, Brazil. Indian J Dent Res. 2014; 25 (5): 648-52.

20- Shifman A, Chanannel I. Prevalence of taurodontism found in radiographic dental examination of 1,200 young adult Israeli patients. Community Dent Oral Epidemiol.1978;6:200-3

21- Goz P W, White S C. In: Oral Radiology (Principle and Interpretation). Ed 3. St Louis, Missouri: C.V. Mosby Year Book Inc; 1994.

22- Burklein S, Breuer D, Schafer E. Prevalence of Taurodont and Pyramidal Molars in a German Population. JOE. 37 (2), 2011;158-62.

23- Brabant H. Comparison of the characteristics and anomalies of the deciduous and permanent dentition. J Dent Res. 1967; 46: 897-902.

24- Bronoosh P, Haghnegahdar A, Dehbozorgi M. Prevalence of Taurodontism in Premolars and Molars in the South of Iran. JODDD, 6(1);2012:21-4. 
25- Mac Donald-Jankowski D S, Li T T. Taurodontism in a young adult Chinese population. Dento Maxillo Radiol.1993;22:140-4.

26- Balis S. Error and accuracy rates of panoramic radiography as a screening method for mass surveying of children. $\mathrm{J}$ Public Health Dent 1981; 41:220-34.

27- Sanderink G C. Imaging characteristics in rotational panoramic radiography. Dento Maxillofac Radiol. 1987; 9(Supp 1):1-213

28- Munir M B, Sajjad I, Sajid M. Prevalence of taurodontism in mandibular second molars. Pakistan Oral Dent J. 2013; 33 (3):528-530.

29- Tsesis I, Shifman A, Kaufman A Y. Taurodontism: an endodontic challenge. Report of a case. JEO. 2003; 29:353-5

30- Thaha K H, Sakkir N, Nair M G, Ajaz A, Parackal L I. Endodontic Management of a Taurodontic Mandibular Second Molar. Concer Dentis Endod J. 2016;1(1):14-7.

31- Hayashi Y. Endodontic treatment in taurodontism. JEO. 1994; 20:357-8. 